\title{
Bed reflectivity beneath inactive ice streams in West Antarctica
}

\author{
Ginny A. Catania, ${ }^{1}$ Howard B. GOnWay, ${ }^{1}$ Anthony M. Gades, ${ }^{1}$ Gharles F. RaymOnd, ${ }^{1}$ \\ HERMANN ENGELHARDT ${ }^{2}$ \\ ${ }^{1}$ Department of Earth and Space Sciences, Box 351310, University of Washington, Seattle, WA 98195-1310, U.S.A. \\ E-mail: ginny@ess.washington.edu \\ ${ }^{2}$ Division of Geological and Planetary Sciences, MC 170-25, California Institute of Technology, Pasadena, CA 91125, U.S.A.
}

\begin{abstract}
Radio-echo sounding (RES) techniques are used to examine spatial changes in bed reflectivity across relict ice streams in West Antarctica. Measurements from adjacent interstream ridges are used to correct the measured power returned from the bed for attenuation and losses due to geometric spreading, scattering and absorption. RES measurements near boreholes drilled on Ice Stream C (ISC) indicate high coefficients of bed reflectivity $(R>0.1)$ in locations where the bed was thawed and boreholes connected to the basal water system, and low reflectivity coefficients $(R<0.02)$ at locations that were frozen and not connected. Intermediate values of bed reflectivity were measured at locations where the connection to the basal water system was weak. Measurements across four relict margins show that bed reflectivity usually jumps from low to high values several kilometers inside the outermost buried crevasses. We interpret this to be a transition from frozen to thawed basal conditions and discuss implications of these observations.
\end{abstract}

\section{INTRODUCTION}

Horizontal surface velocities typically change by more than two orders of magnitude across the margins of active ice streams in West Antarctica, and chaotic surface crevasses form where the shear strain rate exceeds $\sim 0.12 \mathrm{a}^{-1}$ (Echelmeyer and Harrison, 1999). Such changes at the surface require a switch from locked to lubricated conditions at the bed.

Theory suggests that the positions of ice-stream margins are probably not stable if position is controlled only by a transition between frozen and thawed bed (Raymond and others, 2001). Jacobsen and Raymond (1998) discussed processes that might affect the migration of ice-stream margins. One (the so-called "edge-deficit" process) occurs because drag from the sides causes a decrease in basal slip, basal shear stress and production of frictional energy toward the margin, which would favor freezing and inward migration of the margin. In contrast, heat generated by side shearing within the ice column effectively reduces the basal heating necessary to maintain a thawed bed. This "edge-shield" process might promote basal melting outside the margin and allow an ice stream to expand sideways into the surrounding slow-moving ice.

Knowledge of the position of the thawed zone relative to the outermost chaotic crevasses provides insight into the relative importance of these two competing processes. Switches from frozen to thawed conditions at the bed should be detectable using radio-echo sounding (RES), and the aim of this paper is to interpret RES measurements of bed reflection power across several relict ice-stream margins in West Antarctica (Fig. 1). Our ground-based studies focus on inactive ice streams because crevasses have been buried by accumulation subsequent to stagnation, which simplifies the logistics of travel across the surface.
We use observations and measurements from boreholes that have been drilled to the bed of both active and inactive ice streams to help interpret the RES measurements. Boreholes within ice streams reveal thick $(>1 \mathrm{~m})$ layers of water-

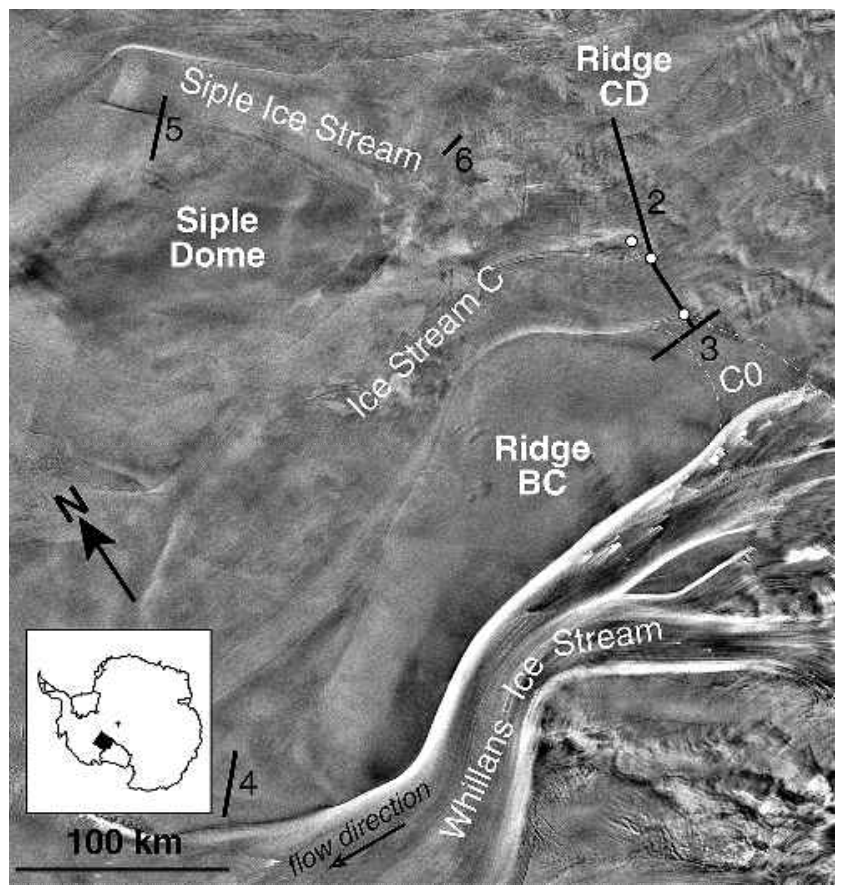

Fig. 1. RADARSAT image of the Siple Coast ice streams in West Antarctica. Numbers next to each radar line (shown as black lines) correspond to the figure number that showes data from that line. Dashed white lines indicate the boundaries of Ice Stream CO. Boreholes discussed in the text are indicated as black circles with white fill. Image courtesy of T. A. Scambos. 

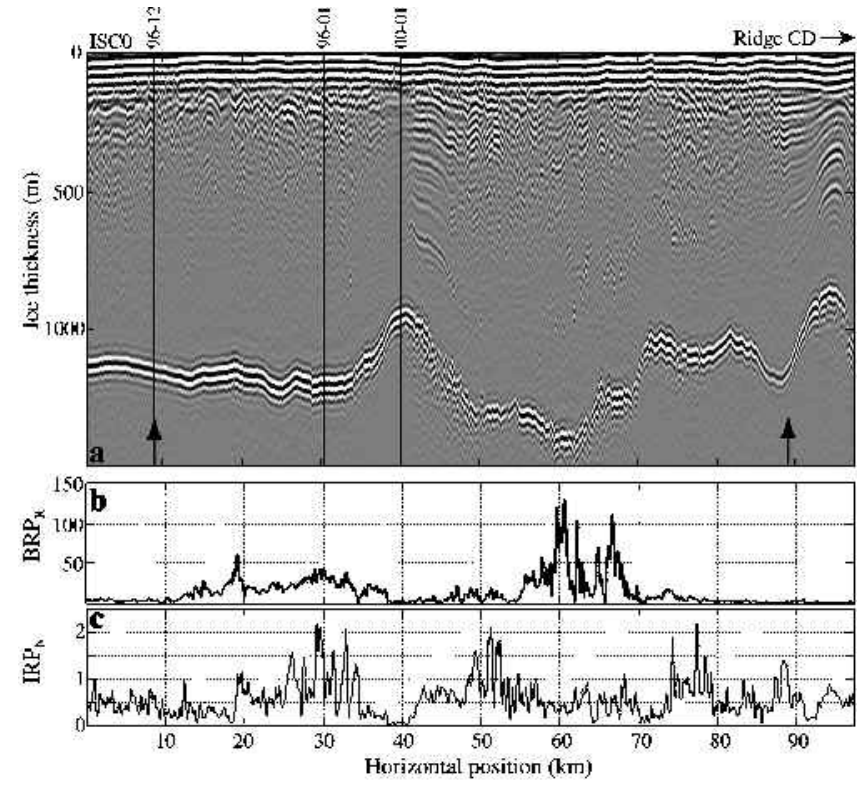

Fig. 2. ( a) $2 \mathrm{MHz}$ RES profile across Ice Stream C starting at $82.76^{\circ} \mathrm{S}, 135.77^{\circ} \mathrm{W}$ and ending at $81.83^{\circ} \mathrm{S}, 136.00^{\circ} \mathrm{W}$. Ridge CD is located at $\mathrm{km} 90$, and the relict tributary ISCO is to the south (near $\mathrm{km} 0$ ). Outer limits of buried near-surface crevasses are indicated by black arrows in Figures 2-6. ( $b$ ) $B R P_{R} ;(c) I R P_{N}$

saturated, dilated till at the base of the ice (Engelhardt and others, 1990b; Engelhardt and Kamb, 1997; Kamb, 2001). In contrast, slow-moving interstream ridges are frozen at the bed; ridges with a history of streaming (e.g. the Unicorn between the two limbs of Whillans Ice Stream) have beds of frozen till, while others with no prior history of streaming (e.g. Siple Dome) are frozen to bedrock (Kamb, 2001).

\section{METHODS}

The power returned from a particular time window in a RES trace is defined following Gades (1998) and Gades and others (2000) to be one-half the sum-of-squared voltage amplitudes divided by the number of samples in the window. The measured power reflected from the bed (BRP) is calculated by centering a hand-selected time window around the reflected bed pulse. BRP is affected by the properties of the system (coupling to surface, antenna frequency), the overlying ice (thickness, temperature, chemistry, presence of crevasses and layer stratigraphy) as well as the properties of the bed (presence of liquid water, water chemistry, type of bed material, bed slope and roughness).

We assume that the coupling between the radar system and the snow surface remains constant across the profiles. This is reasonable since there were no observed changes in snow properties across these areas. Furthermore, we calculate the internal power reflected from the ice column (IRP) within a time window that spans from $2 \mu$ s (just below the air wave) to $0.5 \mu$ s before the shallowest point on the bed. Since changes in BRP might arise from variations in the ice or instrument properties, variations in BRP must be examined in light of any changes in IRP over the same area (Gades and others, 2000).

Radar profiles were collected at frequencies of $\sim 2$ and $\sim 5 \mathrm{MHz}$, and we expect both attenuation and bed reflectivity to be frequency-dependent. To account for this, we simply

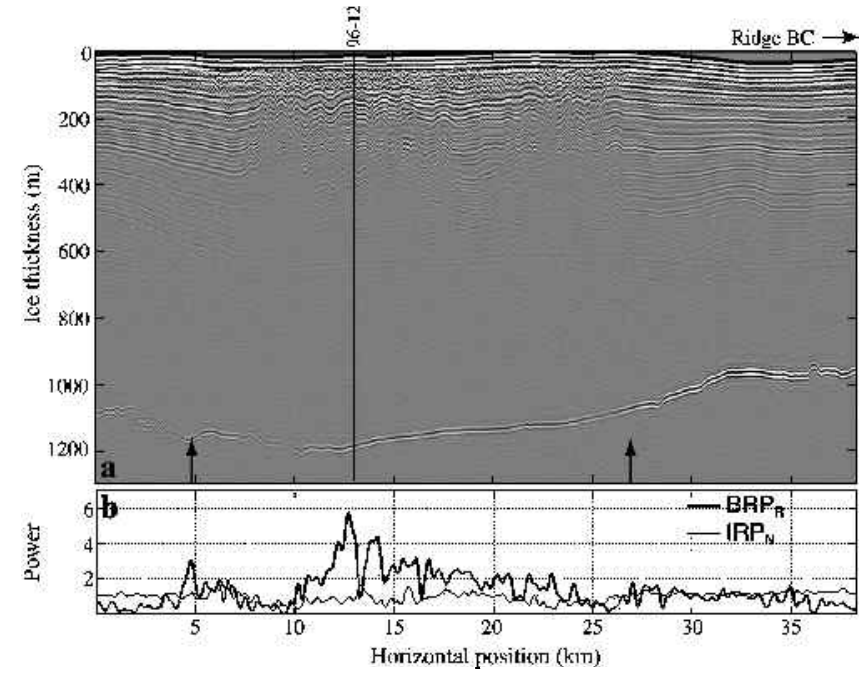

\begin{abstract}
Fig. 3. (a) $5 \mathrm{MHz}$ RES profile across Ice Stream C tributary $C 0$, which used to stream across ridge BC into Ice Stream $C$. This profile starts at $82.79^{\circ} \mathrm{S}, 136.84^{\circ} \mathrm{W}$ and ends at $82.68^{\circ} \mathrm{S}, 134.33^{\circ} \mathrm{W}$. Ridge $B C$ is on the right. (b) $\operatorname{IRP}_{N}$ (thin line) and $B R P_{R}$ (thick line) across the profile.
\end{abstract}

scale the $2 \mathrm{MHz}$ data to match the $5 \mathrm{MHz}$ data using the ratio of the mean bed reflection amplitudes at locations where data were collected at both frequencies.

To correct for the effects of changes in path length we derive an empirical relationship $F(H)$ between the measured BRP and ice thickness $(H)$ using measurements from ridge $\mathrm{BC}$ and Siple Dome. Ice thickness across the two ridges ranges from 600 to $1500 \mathrm{~m}$, and the ice and bed reflection properties are relatively constant, as indicated by the goodness of the fit to $F(H)$ (Gades and others, 2000; Winebrenner and others, in press). BRP at a particular location and frequency is then normalized to yield a depth-corrected relative bed reflectivity $\mathrm{BRP}_{\mathrm{R}}=\mathrm{BRP} / F(H)$ (Gades and others, 2000). For ease of comparison to $B_{R} P_{R}$, IRP is normalized to the mean IRP to calculate $\operatorname{IRP}_{\mathrm{N}}=\mathrm{IPR} /\langle\mathrm{IRP}\rangle$.

RES techniques have been used by others to infer basal conditions beneath glaciers and ice sheets (Bentley and others, 1998; Gades and others, 2000; Copland and Sharp, 2001). Here we examine RES measurements near boreholes that have been drilled to the bed of Ice Stream C and interpret changes in bed reflectivity in the context of measurements and observations from the boreholes. We then use these relationships to infer basal conditions from RES profiles across other relict margins where borehole data are not available.

\section{MEASUREMENTS}

\section{(i) Ice Stream G}

The lower reaches of Ice Stream C (ISG) (Fig. 1) stopped streaming $\sim 150$ years ago (Retzlaff and Bentley, 1993), while a tributary to the ice stream (ISC0) slowed $\sim 250$ years ago (Conway and others, 2002). Figure 2 a shows a radar profile across ISC that starts in the region of ISC0 $(0 \mathrm{~km})$, crosses a bedrock ridge (between $\mathrm{km} 35$ and $\mathrm{km} \mathrm{50)}$ and ends on ridge $\mathrm{CD}$ ( $\mathrm{km}$ 97). Many boreholes were drilled during the $1996 / 97$ and 2000/01 seasons, but only a few of these are located exactly along the RES profile across ISC (96-12 and 96-01 are two of these) (Kamb, 2001).

All of the boreholes drilled within the relict ice stream 
(within $10 \mathrm{~km}$ of borehole $96-01$ at $\mathrm{km} \mathrm{30)}$ connected to a subglacial drainage system (Kamb, 2001). A video camera lowered down one hole in the area revealed a large $(1.4 \mathrm{~m})$ water-filled cavity at the base of the ice with water pressure near the overburden pressure (H. Engelhardt, unpublished data). Thinner water cavities $(\sim 0.05 \mathrm{~m})$ were observed at the bottom of several other boreholes in the vicinity. Ice frozen on to the base of the ice column has been detected in several (but not all) boreholes (Kamb, 2001). This freeze-on ice, which ranges from $\sim 12$ to $25 \mathrm{~m}$ thick, consists of stratified dirty and clean ice layers. Measurements indicate that the $\mathrm{BRP}_{\mathrm{R}}$ in this region is very high $(\sim 20-30)$ and variable (Fig. 2b); it is likely that both the freeze-on ice and variations in the subglacial water content contribute to cause variability in the values of $\mathrm{BRP}_{\mathrm{R}}$ across the ice stream.

The bedrock bump that rises $\sim 270 \mathrm{~m}$ above the surrounding bed (Fig. 2a) is part of a ridge that extends $\sim 50 \mathrm{~km}$ downstream. Borehole 00-01, drilled through the center of the ridge, revealed a frozen bed $(\mathrm{H}$. Engelhardt, unpublished data). This is consistent with measurements of $\mathrm{BRP}_{\mathrm{R}}$ that yield relatively low values $(<2.0)$ across the ridge (Fig. 2b).

Borehole 96-12 (near km 9 in Fig. 2a) was drilled outside the most recent margin of ISG but within ISC0. Connection to the subglacial drainage system at this borehole was weak (Kamb, 2001). Values of $\mathrm{BRP}_{\mathrm{R}}$ calculated in this region ( $\sim 6.0$; see Fig. 3$)$ are intermediate between regions that are thought to be totally frozen and those that are thawed.

Figure 3 shows a radar profile across ISC0 that starts and ends in undisturbed ridge ice. The outer limits of buried surface crevasses, detected by high-frequency $(100 \mathrm{MHz})$ radar, are at $\mathrm{km} 4.9$ and $\mathrm{km} 27 . \mathrm{BRP}_{\mathrm{R}}$ across this inactive tributary are generally much lower than those across ISC (discussed above), although intermediate values $(\sim 6.0)$ in the deepest section of the bedrock trough located near the eastern margin of the ice stream (Fig. 3b) suggest that the bed there is still partly thawed.

\section{(ii) Whillans Ice Stream}

Whillans Ice Stream (WIS; formerly known as Ice Stream B) is still actively streaming, but radar profiles (Fig. 4) across visible scar features near the present grounding line on ridge BC (Fig. 1) show that the active margin has migrated inward in recent times. Buried crevasses detected by high-frequency $(100 \mathrm{MHz})$ radar indicate at least two distinct paleo-margins: one at $\mathrm{km} 4.8$ where the tops of crevasses are buried $\sim 70 \mathrm{~m}$ below the surface, and another at $\mathrm{km} \mathrm{17}$, where crevasses are $\sim 30 \mathrm{~m}$ below the surface. The more recent margin (at $\mathrm{km} \mathrm{17)}$ was probably abandoned at about the same time as ISC stagnated ( $~ 150$ years ago), while the older margin must be $>600$ years old (assuming typical accumulation rates for the area). It is possible that the ice stream was even wider in the more distant past, because the internal layers in the flat ice region outside of the former margins also show evidence of disturbance (Fig. 4).

Measurements indicate that the $\mathrm{BRP}_{\mathrm{R}}$ remains relatively low until $\mathrm{km} \mathrm{13}$, which is about $8 \mathrm{~km}$ within the oldest paleomargin (defined by the outer buried crevasses at $\mathrm{km} \mathrm{4.8).}$ $\mathrm{BRP}_{\mathrm{R}}$ increases to $\sim 5.0$ but remains variable. Variability may be a result of bed roughness as evidenced by the point diffractors visible at the bed (Fig. 4). Using the observations and measurements from ISC as a guide to interpret values of $\mathrm{BRP}_{\mathrm{R}}$, we infer a frozen bed between $\mathrm{km} 0$ and $\mathrm{km} 11$, and an

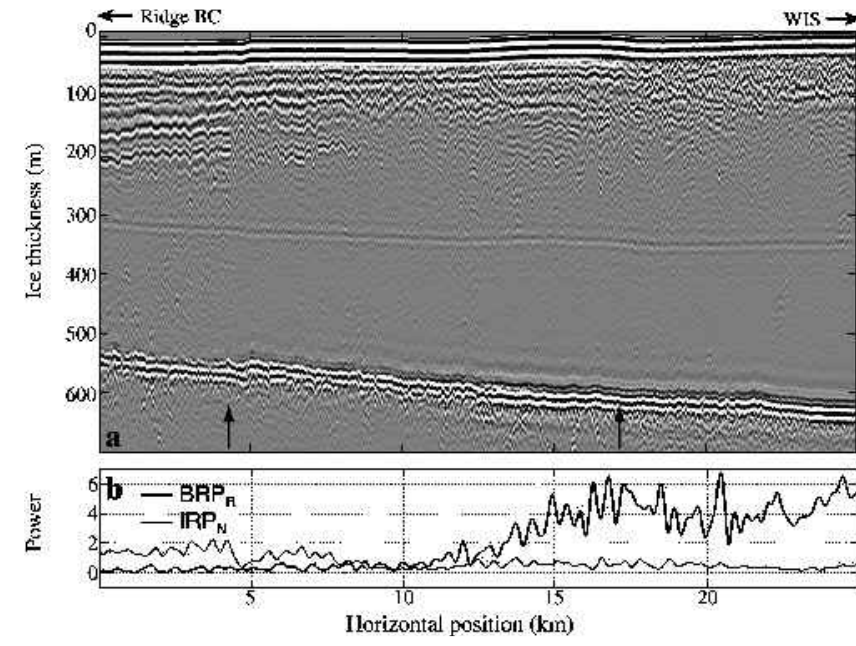

Fig. 4. (a) $5 \mathrm{MHz}$ RES profile across two relict margins of Whillans Ice Stream starting at $83.47^{\circ} \mathrm{S}, 155.21^{\circ} \mathrm{W}$ and ending at $83.65^{\circ} \mathrm{S}, 156.94^{\circ} \mathrm{W}$. The active northern margin of WIS is farther east ( at $\sim k m 40)$. Note the prominent return about $\sim 300 \mathrm{~m}$ below the surface is a glitch in the radar system. (b) $I R P_{N}$ (thin line) and $B R P_{R}$ (thick line) across the profile.

intermediate condition (similar to those at BH 96-12 where the connection to the bed was weak) between $\mathrm{km} 11$ and $\mathrm{km} 25$.

\section{(iii) Siple Ice Stream}

Siple Ice Stream (SIS) slowed about 450 years ago (Smith, 2000); Figures 5 and 6 show radar profiles across the western and eastern margins of the former ice stream. Figure 5 shows an abrupt increase in $\mathrm{BRP}_{\mathrm{R}}$ (to $\sim 6.0$ ) across the western margin about $4 \mathrm{~km}$ into the ice stream (beyond the outer limit of chaotic crevasses); again we interpret this to indicate a transition from frozen to partly frozen conditions at the bed. The transition is not so obvious across the eastern margin (Fig. 6) where, although the $\mathrm{BRP}_{\mathrm{R}}$ does increase about $4 \mathrm{~km}$ into the ice stream, the maximum value is only $\sim 2.0$, suggesting that the bed here is probably more frozen.

\section{DISGUSSION}

Tulaczyk and others (2000a,b) believe that ISG stagnated when the basal energy gradient switched from a melting to a freezing environment, because even small amounts of freezing can reduce the till porosity and this can have a large impact on its strength. Hence an ice stream might slow long before its bed is completely frozen, and liquid water remaining at the bed would keep it highly reflective. With ongoing freezing, the spatial extent of the basal water is expected to decrease, and high bed reflectivity might occur only in regions where water has ponded, such as beneath deep sections of an ice stream (as observed near km 65 in Fig. 2).

RES profiles, together with measurements and observations from boreholes on ISC, strongly support the notion that much of the measured increase in $\mathrm{BRP}_{\mathrm{R}}$ beneath the inactive ice streams is caused by the presence of subglacial water systems with various degrees of connectivity. We interpret regions of low bed reflectivity $\left(\mathrm{BRP}_{\mathrm{R}}<2.0\right)$ to be frozen at the bed, and high reflectivity $\left(\mathrm{BRP}_{\mathrm{R}}>6.0\right)$ to be distinctly wet. Intermediate values of bed reflectivity indicate basal conditions that lie between these two regimes. 

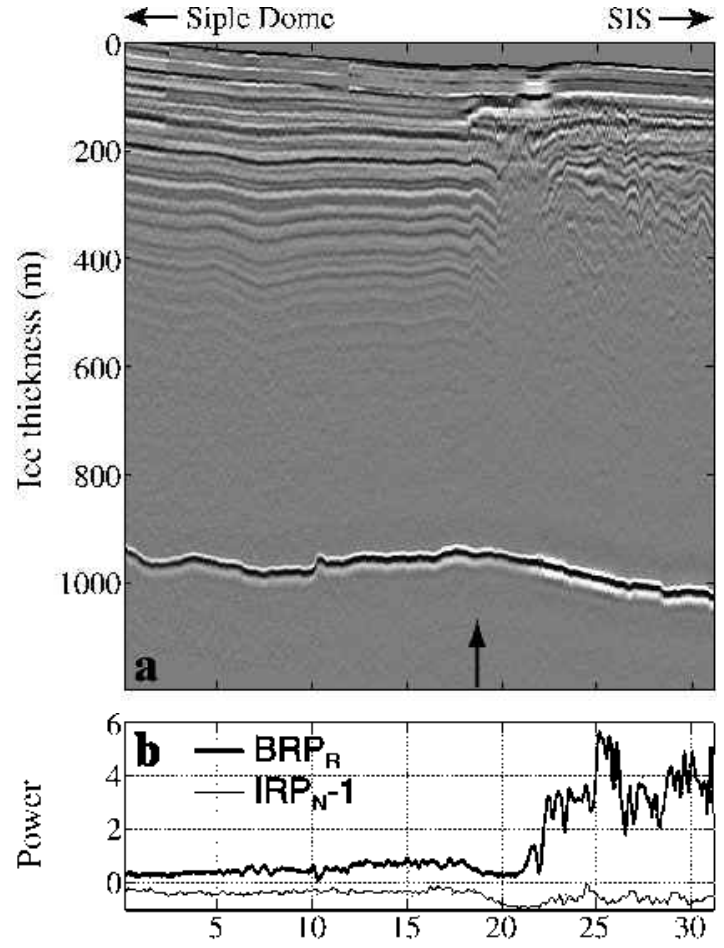

Horizontal position ( $\mathrm{km}$ )

Fig. 5. (a) $2 \mathrm{MHz}$ RES profile across the western margin of Siple Ice Stream from $81.29^{\circ} \mathrm{S}, 148.09^{\circ} \mathrm{W}$ and ending at $81.08^{\circ} \mathrm{S}, 147.01^{\circ} \mathrm{W}$. The flank of Siple Dome is to the left. (b) $I R P_{N}$ (thin line) and $B R P_{R}$ (thick line) across the profile; note that $I R P_{N}$ has been shifted down by 1 for display purposes in Figures 5 and 6. These data were also previously examined by Gades and others (2000).

Measurements by Echelmeyer and others (1994) and Echelmeyer and Harrison (1999) across an active margin of WIS show surface velocities increasing from near zero to $>10^{2} \mathrm{~m} \mathrm{a}^{-1}$ within a few kilometers. The outer edge of chaotic crevassing corresponds to the position where transverse velocity gradients reach values of $\sim 0.12 \mathrm{a}^{-1}$. This location is about $1 \mathrm{~km}$ from where the velocity first starts to increase. The structure of the velocity profile across a margin depends on both the spatial distribution of basal shear stress and the stiffness of the overlying ice column, but model results suggest that basal slip resistance likely changes within a few kilometers of the outermost chaotic crevasses (Echelmeyer and others, 1994; Raymond, 1996). If their results are typical for active margins, we expect to observe a jump in $B R P_{R}$ within about $2 \mathrm{~km}$ of the outer edge of the chaotic crevasses.

The jump in bed reflectivity from low values $\left(\mathrm{BRP}_{\mathrm{R}} \leq 1\right)$ beneath ridges to high values $\left(\mathrm{BRP}_{\mathrm{R}}>2\right)$ beneath the relict ice streams presumably delineates the transition from frozen to thawed conditions at the bed. In most cases studied here (the profile across the eastern margin of ISC0 is an exception) the thawed/frozen transition occurred 4-10 km inside the outer edge of chaotic crevasses.

It is possible that the frozen/thawed boundary has migrated inward subsequent to the shut-down of the ice streams studied here. It is also possible that the margins migrated inward prior to shut-down, thus contributing to the slowing and eventual stoppage of the ice stream. Freezing at a margin is expected if the frictional energy produced by sliding is not sufficient to maintain thawed conditions at the bed (Jacobson and Raymond, 1998). For conditions typical of West Antarctica, energy production reaches a critical
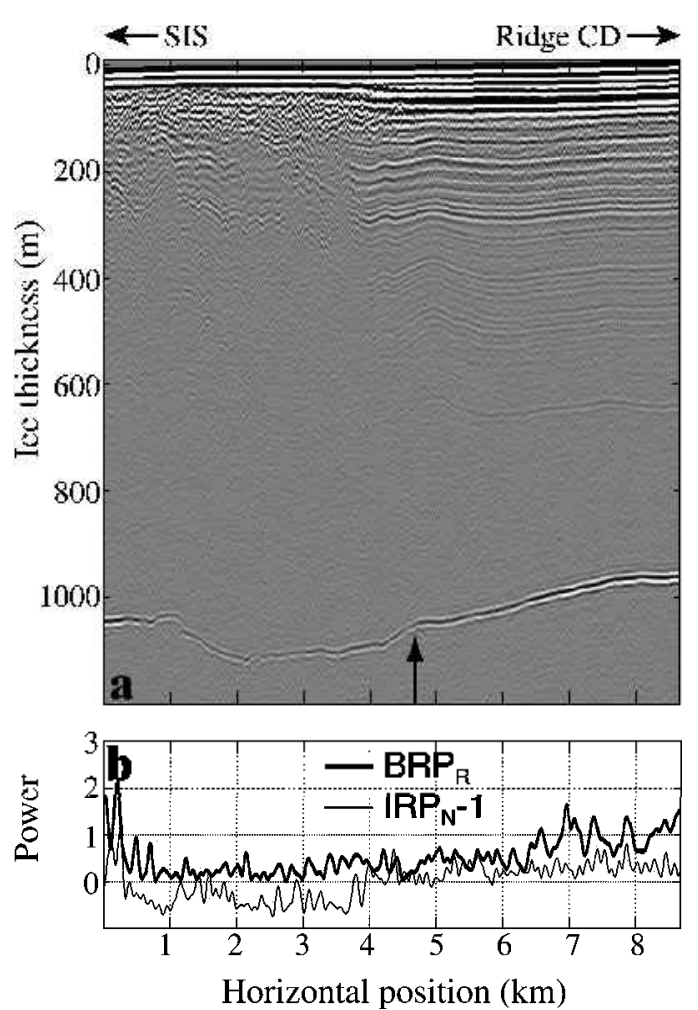

Fig. 6. (a) $5 \mathrm{MHz}$ RES profile across the eastern margin of Siple Ice Stream starting at $81.70^{\circ} \mathrm{S}, 140.12^{\circ} \mathrm{W}$ and ending at $81.75^{\circ} \mathrm{S}, 140.84^{\circ} \mathrm{W}$. Ridge $C D$ is on the right. (b) $I R P_{N}$ (thin line) and $B R P_{R}$ (thick line) across the profile.

value when an ice stream slows to $\sim 10^{2} \mathrm{~m} \mathrm{a}^{-1}$ (sooner if cold ice is advected across the margin into the ice stream).

It is not clear why the $\mathrm{BRP}_{\mathrm{R}}$ beneath the trunk region of ISC is so bright (up to two orders of magnitude higher than the ridges in the deep trough near $\mathrm{km} 60$ in Fig. 2). The power reflection coefficient $R$ from a perfect reflector is 1.0, although physically we expect a maximum value of $R=0.8$ (Gades, 1998). Assuming that values of $\mathrm{BRP}_{\mathrm{R}}$ beneath ISC are a maximum, at Siple Dome (with $\mathrm{BRP}_{\mathrm{R}}$ roughly 0.01 of ISG) $R$ must be $<0.008$, which is about one-tenth of the value estimated by Gades and others (2000).

It is possible that such low $\mathrm{BRP}_{\mathrm{R}}$ values are a result of overestimating the attenuation and losses associated with the travel path. However, measurements from airborne RES also indicate high bed reflectivity beneath ISC; in fact values are significantly higher than beneath WIS (Bentley and others, 1998), which is still actively streaming. Another possibility is that the overlying ice column is relatively transparent to radar waves, although calculations of IRP $P_{N}$ across the ice stream (Fig. 2c) do not exhibit anomalous values. A third possibility is that the water beneath ISG is much more conductive and/or thicker than that beneath WIS. The conductivity of basal water beneath WIS ( $\sim 0.025 \mathrm{Sm}^{-1}$; Engelhardt and others, 1990a) would yield values of $R \sim 0.1-0.2$ for physically reasonable values of water thickness (Gades, 1998). Water of higher conductivity, such as that for sea water $\left(\sim 3-4 \mathrm{Sm}^{-1}\right)$, would be necessary to yield $R \sim 0$.8. It is possible that the conductivity of water beneath ISC is very high because the solutes are not being flushed out by a through-flowing basal water system.

The inferred presence of liquid water across $>75 \%$ of the bed of ISG raises the possibility that the ice-stream system is metastable. The time-scale for freezing all of the water at the bed might be such that an inactive ice stream 
can exist for hundreds of years in a subcritical state, during which relatively small perturbations in driving stress or lubrication could reactivate fast flow.

\section{ACKNOWLEDGEMENTS}

We thank T. A. Scambos, M. Conway and R. L. Hawley for valuable contributions. We also thank D. G. Vaughan and L. Copeland for careful reviews, and T. Murray for editing. This work was supported by the U.S. National Science Foundation (grants OPP-9909469, OPP-9615347 and OPP9615420).

\section{REFERENCES}

Bentley, C. R., N. Lord and C. Liu. 1998. Radar reflections reveal a wet bed beneath stagnant Ice Stream $\mathrm{C}$ and a frozen bed beneath ridge BC, West Antarctica. f. Glaciol., 44(146), 149-156.

Conway, H., G. Catania, C. Raymond, T. Scambos, H. Engelhardt and A. Gades. 2002. Switch of flow direction in an Antarctic ice stream. Nature, 419(6906), 465-467.

Copland, L. and M. Sharp. 2001. Mapping thermal and hydrological conditions beneath a polythermal glacier with radio-echo sounding. $\mathcal{F}$ Glaciol., 47(157), 232-242.

Echelmeyer, K. A. and W. D. Harrison. 1999. Ongoing margin migration of Ice Stream B, Antarctica. F. Glaciol., 45(150), 361-369.

Echelmeyer, K. A., W. D. Harrison, C. Larsen and J. E. Mitchell. 1994. The role of the margins in the dynamics of an active ice stream. F. Glaciol., 40 (136), 527-538.

Engelhardt, H. and B. Kamb. 1997. Basal hydraulic system of a West Antarctic ice stream: constraints from borehole observations. F. Glaciol., 43(144), 207-230.

Engelhardt, H., N. Humphrey and B. Kamb. 1990a. Borehole geophysical observations on Ice Stream B, Antarctica. Antarct. 7. U.S., 25(5), 80-82.

Engelhardt, H., N. Humphrey, B. Kamb and M. Fahnestock. 1990b. Physical conditions at the base of a fast moving Antarctic ice stream. Science, 248(4951), 57-59.

Gades, A. M. 1998. Spatial and temporal variations of basal conditions beneath glaciers and ice sheets inferred from radio echo soundings. (Ph.D. thesis, University of Washington.

Gades, A. M., C. F. Raymond, H. Conway and R. W. Jacobel. 2000. Bed properties of Siple Dome and adjacent ice streams, West Antarctica, inferred from radio-echo sounding measurements. 7. Glaciol., 46(152), 88-94.

Jacobson, H. P. and C. F. Raymond. 1998. Thermal effects on the location of ice stream margins. 7. Geophys. Res., 103(B6), 12,111-12,122.

Kamb, B. 2001. Basal zone of the West Antarctic ice streams and its role in lubrication of their rapid motion. In Alley, R. B. and R. A. Bindschadler, eds. The West Antarctic ice sheet: behavior and environment. Washington, DC, American Geophysical Union, 157-199. (Antarctic Research Series 77.)

Raymond, C. 1996. Shear margins in glaciers and ice sheets. 7. Glaciol., 42(140), 90-102.

Raymond, C. F., K. A. Echelmeyer, I. M. Whillans and C. S. M. Doake. 2001. Ice stream shear margins. In Alley, R. B. and R. A. Bindschadler, eds. The West Antarctic ice sheet: behavior and environment. Washington, DC, American Geophysical Union, 137-155. (Antarctic Research Series 77.)

Retzlaff, R. and C. R. Bentley. 1993. Timing of stagnation of Ice Stream C, West Antarctica, from short-pulse radar studies of buried surface crevasses. F. Glaciol., 39(133), 553-561.

Smith, B. 2000. Radar studies on Ice Stream C, West Antarctica. (M.Sc. thesis, University of Wisconsin-Madison.)

Tulaczyk, S. M., B. Kamb and H. F. Engelhardt. 2000a. Basal mechanics of Ice Stream B, West Antarctica. I. Till mechanics. 7. Geophys. Res., 105(B1), 463-481.

Tulaczyk, S. M., B. Kamb and H. F. Engelhardt. 2000b. Basal mechanics of Ice Stream B, West Antarctica. II. Undrained-plastic-bed model. 7. Geophys. Res., 105(Bl), 483-494.

Winebrenner, D. P., B. Smith, G. Catania, H. Conway and C. F. Raymond. In press. Radio-frequency attenuation beneath Siple Dome, West Antarctica, from wide-angle and profiling radar observations. Ann. Glaciol., 37. 